\title{
DIAGNOSTICS OF RISKY PARENTAL REARING STYLE IN DENTAL PRACTICE
}

\author{
Milena Georgieva, \\ Department of Paediatric Dentistry, Faculty of Dental Medicine, Medical \\ University of Sofia, Bulgaria.
}

\section{SUMMERY:}

The aim of this study is diagnostics of risky parental behaviour for negative behaviour forming of children in dental practice.

Methods and materials: Diagnostics of risky parental behaviour was determined in 100 children and their children, who signature inform consent. There are two questionnaires for parents and children. The parental test is eight questions determined elements of parental style which correlate mostly with childish negative behaviour in dental office. Children's test consists of seven questions based on proved elements of upbringing forming negative behavior. It was established that the highest the score is the biggest risk will occur. We find out that $45,35 \%$ of parent give evidence for attendance of high risk and 63,45\% of children are risky for negative behaviour. Conclusion: Correct diagnostics will lead to correct modelling of parental style which facilitates dental treatment. This determines the importance of an early diagnostics of various forms of risky parental behaviour.

Keywords: parent- child interaction, rearing style, negative behaviour,

\section{INTRODUCTION}

Infant upbringing in the family has influence over childish behavior $[1,2,3]$. The preschool children do not have the ability to understand the situation and they are little concern with the effect of their behaviour in dental office $[5,9]$. Parents use certain methods which lead to forming of negative behaviour must require behaviour modelling for avoid complication in dental office $[4,5,6]$. This could be achieved with the necessary knowledge and skills of the dentist who directs attention to emotional interaction between child and parents. This way we will realize effective interaction between dentist, parents and child-patient $[7,8,9]$. There are different written and oral forms for parental instructions which is used for modelling parental behaviour when methods for children behaviour management are used [10, 11].
Aim:

The aim of the study is diagnostics of risky parental behaviour for negative behaviour forming of children in dental practice.

\section{MATERIAL AND METHODS}

The study was conducted among 100 children between 4 and 6 years old and their parents, which was collected on casual principle from three kinder gardens in Sofia who gave their written consent. All parents were female. Parents were asked to filled out questionnaire about their rearing practice. Using the correlation from our previous investigation we find out eight questions from our parental test which is connected to negative behaviour [Table 1]. They are elements authoritarian and overprotective style. There is information about parental caring, concern and discipline. The questionnaire should be included to the history of the disease during the first dental visit.

Parent fills the test during the exam. Each answer which shows risky behaviour gives 2 points and those without risk gives 0 points. All answers are summed and higher score means higher usage of risky rearing practice. The highest score means risky education is 16 , minimum is 0 . Determination of the risk is this way: low risk- from 0 to 6 , medium risk - from 7 to 12 and high risk - from 13 to 18 points. This is the way to find out the risk of forming negative behaviour as a result of incorrect education.

Thirty children were girls and seventy were boys. Children's test consists of seven questions, which testified for another element of parental rearing which is proved to lead to negative behaviour in dental practice. Children filled the test in the dental office. Using this proved elements of rearing from our previous investigation, which form negative behaviour we made the childish test [Table 2].

Test consists of 7 questions and risky behaviour is given 2 points while those without risk is -0 points. Maximum points are 14 , minimum is 0 . Determination of the risk is again divided into three groups: low risk- from 0 to 4 , medium risk - from 5 to 8 and high risk - from 9 to 14 points.

The collected data were analyzed with SPSS Program version 19. Alternative and correlation analysis were used. 


\section{RESULTS AND DISCUSSION}

Table 1. Parental test for diagnostics of risky upbringing leads to negative children's behavior in dental practice.

\begin{tabular}{|c|c|c|c|}
\hline \multicolumn{2}{|r|}{ Questions } & \multicolumn{2}{|c|}{ Points } \\
\hline 1. & Are you too anxious about your children health? & Yes -2 & No -0 \\
\hline 2. & Do you have patience to listen to your child problems? & Yes - 0 & No - 2 \\
\hline 3. & Do you have great expectation from the child? & Yes - 2 & No -0 \\
\hline 4. & Do you think that every problem has its solution? & Yes - 0 & No - 2 \\
\hline 5. & Do you feel that sometimes beating is a method to educate children? & Yes - 2 & No - 0 \\
\hline 6. & Do you feel annoyed when your child does' not obey the rules? & Yes - 2 & No - 0 \\
\hline 7. & Do you hide your family problems from the child? & Yes - 2 & No -0 \\
\hline 8. & If you make mistake do you find guilty in front of the child? & Yes - 0 & No -2 \\
\hline
\end{tabular}

Table 2 Childish test for diagnostics of risky upbringing leads to negative childish behavior in a dental office

\begin{tabular}{|c|c|c|c|}
\hline \multicolumn{2}{|r|}{ Questions } & \multicolumn{2}{|c|}{ Points } \\
\hline 1. & Do you parents allow you do what you want? & Yes-0 & No-2 \\
\hline 2. & Do your parents explain you why you have to do something? & Yes-0 & No-2 \\
\hline 3. & Do your parents help you even when you can do something? & Yes-2 & No-0 \\
\hline 4. & Are your parents interested in your friends? & Yes-0 & No-2 \\
\hline 5. & Do your parents love you even if you have bad behaviour? & Yes-0 & No-2 \\
\hline 6. & Are you punished if you make mistakes? & Yes-2 & No-0 \\
\hline 7. & Do your parents make you calm when you are upset? & Yes-0 & No-2 \\
\hline
\end{tabular}

Fig. 1. Distribution of parents according to their risky rearing

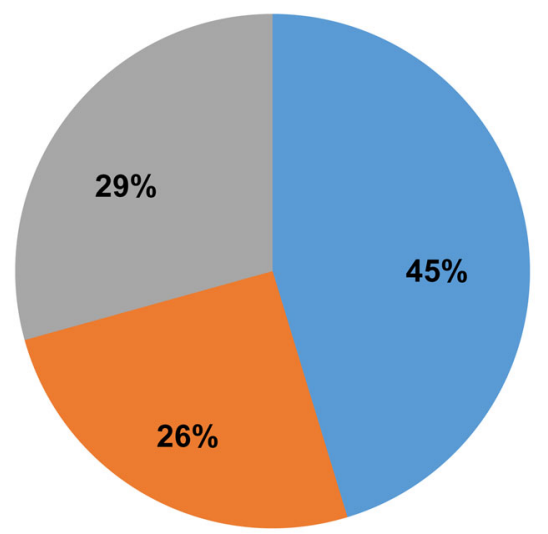

$\square 45,35 \%$ high risk $₫ 25,4 \%$ medium risk $₫ 29,35 \%$ low risk

There is risk of development of negative behaviour when parents are in medium and high risk which means that parents have total from 7 to 18 points. More than a half of the parents, about $71 \%$, which is the group of high and medium risk, show risky behaviour in dental office (fig 1). Risky children whose parents have specific behaviour problems are more likely to have the same problems [8]. We detected that children whose parents have specific behaviour problems are more likely to have the same problems. There are two questions which have positive answers among the risky group - question one and three. The first one reveals parents concern and anxiety about children health. The second is about parents' great expectation. Low risky parents are $29 \%$. It is assumed that they are optimistic and they are interested in the life of their children.

All the parents from low risky group answer that they don't use beating as a discipline method. When they are asked about better methods for discipline they confess: talk to influence the child, bribe the child, use positive reinforcement. It was proven that if the child is respected have happier dispositions, greater emotional control and regulation, and improved social skills, all of which would suggest they would behave better at the dental office $[4,8]$. 
Fig. 2. Distribution of children according to their risky parental rearing

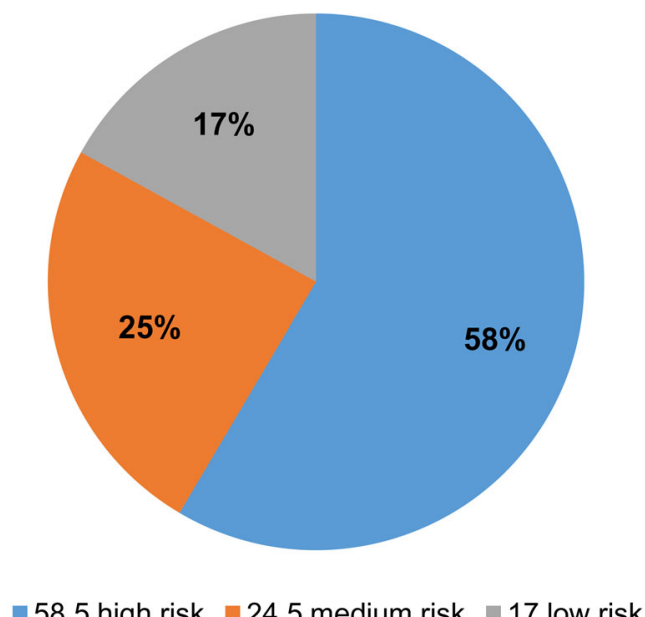

Children had significally higher score than their parents. This results indicate that the children are honest and answered the questions truthfully. According to the date high risky patients are $58,5 \%$ (fig.2). The distribution of participants is presented in the Fig.2. It was found that approximately $17 \%$ of the children had low risky parenting. Parents of low risky children are empathic and may calm their child very well. It is very important characteristic of the parent especially if the child is very young and close person will give the child confidence, mental and social support, and dispel the child's fears. The important prerequisite is that such persons are able to calm down the child, encourage him/her and make fun. Such parents and grandparents are of invaluable help and make work for the dentist much easier [2, 3, 8].

Another risky element of upbringing is help your child even if your child doesn't need help and concerns explication of things which have to be done. About $87 \%$ of children answered that their parents behave like overprotective parents, which means that even in low risky group we have such parents. Risky children are negative about enforce obedience, when they have to do something without any explications about meaning and need. Overprotective parenting is very serious risk for creating of negative behaviour [7]. Letting the children make mistakes strengthen their resolve and build their confidence [4]. This results show that when children are not forced to do something they are more willing to cooperate [5].

The demand of parents for safer and less aggressive techniques is consistent with the increasing emphasis on children's rights and informed consent liability [6]. However, the effectiveness of these parental behavior management is not known and more research is needed.

For gaining parents' tolerance toward behaviour management technique, Peretz and Zadik suggested detailed explanation and witnessing children during dental treatment [11]. The current study and our previous study propose effective and nonaggressive method for parents' involvement in dental treatment of children including those who are highly anxious [7]. This method is very appropriate for preschool age when the parent-child interaction is very important for child to develop optimally.

\section{CONCLUSION:}

Assessment of behavior is the most important tool in the hands of pediatric dentist. Negative behavior forming is a result of many factors. Elements of authoritative and overprotective rearing style are risky for forming negative behavior in dental practice. Correct diagnostics will lead to correct modelling of parental style which will facilitate dental treatment.

\section{REFERENCES:}

1. AAPD. Originating Council. Policy on pediatric pain management. Pediatr Dent. 2015; 37(6-15/16):823. [Internet]

2. Aminabadi NA, Deljavan AS, Jamali Z, Azar FP, Oskouei SG. The Influence of Parenting Style and Child Temperament on Child-ParentDentist Interactions. Pediatr Dent. 2015 Jul-Aug;37(4):342-7. [PubMed]

3. Baier K, Milgrom P, Russell S, Mancl L, Yoshida T. Children's fear and behavior in private pediatric dentistry practices. Pediatr Dent. 2004 Jul-Aug;26(4):316-21. [PubMed]

4. Bornstein M. Handbook on Parenting: children and parenting.
Mahwah NJ: Lawrence Erlbaum Publishers, 2002,1, 269.

5. Chadwick BL, Hosey MT. Child Taming: How to Manage Children in Dental Practice (Quintessentials of Dental Practice Vol 9): How to Cope with Children in Dental Practice (Englisch) Gebundene Ausgabe Illustriert, 31. Januar 2003.

6. Eaton JJ, McTigue DJ, Fields HW Jr, Beck M. Attitudes of contemporary parents toward behavior management techniques used in pediatric dentistry. Pediatr Dent. 2005 MarApr;27(2):107-13. [PubMed]

7. Georgieva M, Peneva M. Parental authoritarian style influence on children behavior in dental office.
Medinform. 2016: 3(2):499-505. [CrossRef]

8. Hammond SI, Muller U, Carpendale JI, Bibok MB, Liebermann-Finestone DP. The effects of parental scaffolding on preschoolers' executive function. Dev Psychol. 2012 Jan;48(1):271-81. [PubMed] [CrossRef]

9. Klingberg G, Raadal M. Behavior management problems in children and adolescents. In: Pediatric dentistry: a clinical approach. Editors Koch G, Poulsen S. 1 st ed. Copenhagen: Munksgaard, 2001.

10. Landry SH, Smith KE, Swank PR, Zucker T, Crawford AD, Solari EF. 
The effects of a responsive parenting intervention on parent-child interactions during shared book reading. Dev Psychol. 2012 Jul;48(4):969-86. [PubMed] [CrossRef]
11. Peretz B, Zadik D. Parents' attitudes toward behavior management techniques during dental treatment. Pediatr Dent. 1999 May-Jun; 21(3): 201-4. [PubMed]

Please cite this article as: Georgieva M. Diagnostics of risky parental rearing style in dental practice. J of IMAB. 2018 Jul-Sep;24(3):2109-2112. DOI: https://doi.org/10.5272/jimab.2018243.2109

Received: 16/05/2018; Published online: 19/08/2018

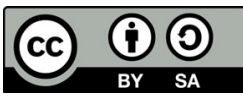

Address for correspondence:

Milena Georgieva

Department of Pediatric Dentistry, Faculty of Dental Medicine, Medical University of Sofia.

1, Georgi Sofiiski str., Sofia, Bulgaria.

E-mail: mmeni@abv.bg 